\title{
HISTORIC BIM: A NEW REPOSITORY FOR STRUCTURAL HEALTH MONITORING
}

\author{
F. Banfi ${ }^{\text {a }}$ L. Barazzetti ${ }^{\text {a }}$, M. Previtali* a, F. Roncoroni ${ }^{\text {b }}$ \\ ${ }^{a}$ Dept. of Architecture, Built environment and Construction engineering (ABC) Politecnico di Milano, \\ Piazza Leonardo da Vinci 32, Milan, Italy \\ ${ }^{b}$ Polo Territoriale di Lecco, via Previati 1/c, Lecco \\ (fabrizio.banfi, luigi.barazzetti, mattia.previtali, fabio.roncoroni)@ polimi.it \\ http://www.gicarus.polimi.it
}

KEY WORDS: Archive, BIM, Bridge, HBIM, Monitoring, Repository

\begin{abstract}
:
Recent developments in Building Information Modelling (BIM) technologies are facilitating the management of historic complex structures using new applications. This paper proposes a generative method combining the morphological and typological aspects of the historic buildings (H-BIM), with a set of monitoring information. This combination of 3D digital survey, parametric modelling and monitoring datasets allows for the development of a system for archiving and visualizing structural health monitoring (SHM) data (Fig. 1). The availability of a BIM database allows one to integrate a different kind of data stored in different ways (e.g. reports, tables, graphs, etc.) with a representation directly connected to the 3D model of the structure with appropriate levels of detail (LoD). Data can be interactively accessed by selecting specific objects of the BIM, i.e. connecting the 3D position of the sensors installed with additional digital documentation. Such innovative BIM objects, which form a new BIM family for SHM, can be then reused in other projects, facilitating data archiving and exploitation of data acquired and processed. The application of advanced modeling techniques allows for the reduction of time and costs of the generation process, and support cooperation between different disciplines using a central workspace. However, it also reveals new challenges for parametric software and exchange formats. The case study presented is the medieval bridge Azzone Visconti in Lecco (Italy), in which multi-temporal vertical movements during load testing were integrated into H-BIM.
\end{abstract}

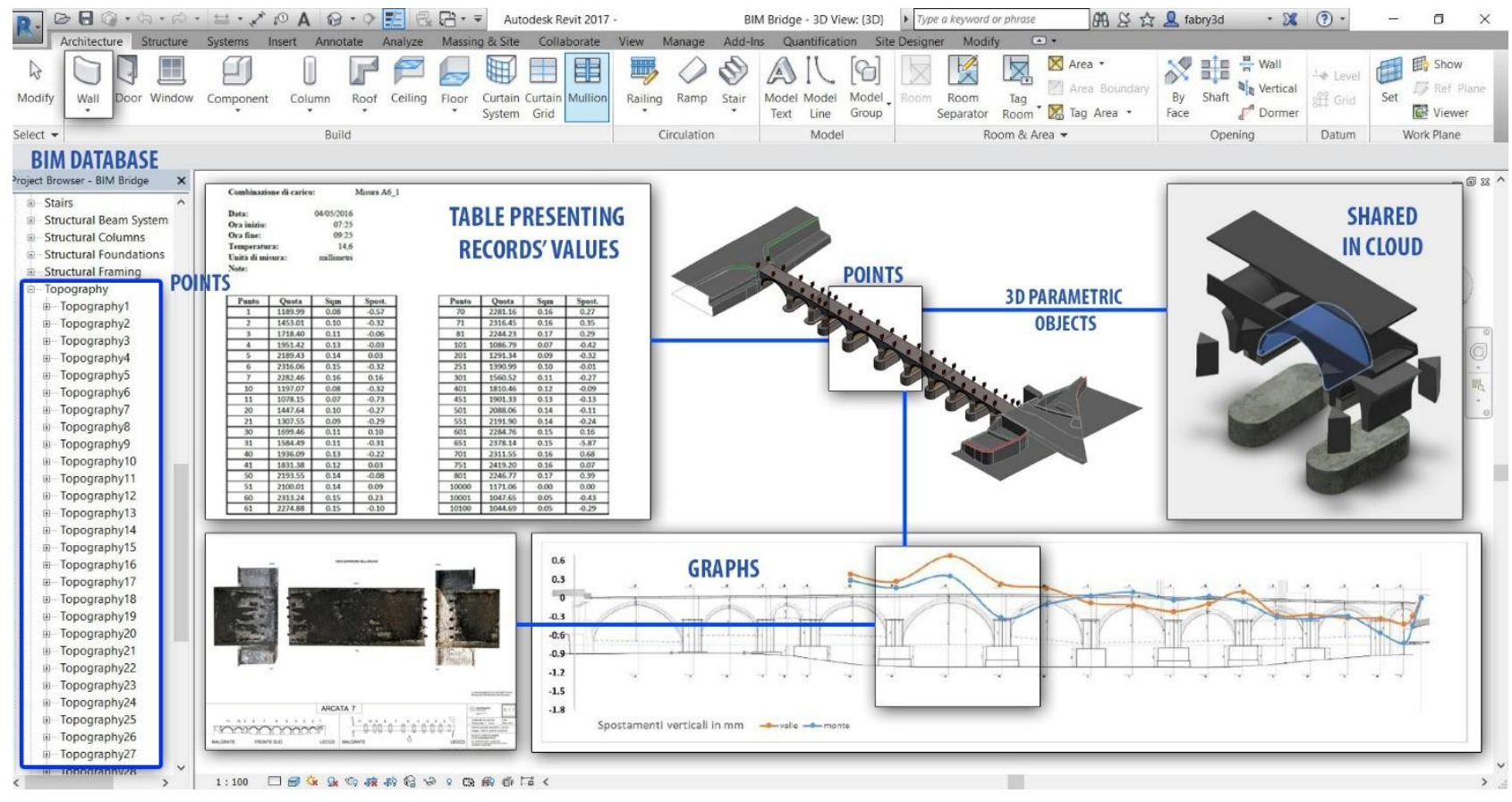

Fig. 1. The Historic BIM of Ponte Azzone Visconti in Lecco. The connection between model, leveling benchmarks and results after least squares adjustment of leveling network.

\section{INTRODUCTION}

H-BIM and modelling applications are changing the Architecture, Engineering and Construction (AEC) sector. The implementation of building information modelling as a cultural process with a focus on the new procedures for built heritage and the technology's impact. H-BIM changes not only the process, technology and organization of the leadership playing field but also the transmissibility of the information during the life cycle of the structure. A collaborative digital work space is improving specific promising occupations such as $3 \mathrm{D}$ surveyor and BIM

* corresponding author 
manager, as well as creating new advanced Information Technology (IT) skills useful for solving communication problems at work. The sharing of the intangible value of the built heritage is the principal purpose of new professional users. All these aspects are encouraging the re-engineering of various fields related to preservation, restoration, and conservation of the historical built environment. BIM technology is also harmonizing the international legislation and ensuring safe and efficacious rehabilitation projects of significant historic structures and modest vernacular buildings.

The main goal of this research is to create a new methodology able to improve the tangible and intangible values of Azzone Visconti Bridge in Lecco. In particular, this study represents a new generative and management process of a complex structure through knowledge of, and respect for, our common history, international values and the recent development of new technologies. They bring opportunities for the economy and for creating new innovative visions for work process, making culture accessible to a large number of well-chosen qualified experts of architecture, engineering and construction sector.

Three dimensional survey, advanced modelling techniques, BIMs, web share Cloud and related technologies are interoperable constituents of the proposed integrated approach based on a new repository for structural health monitoring.

\section{DATA ACQUISITION AND REGISTRATION}

\subsection{Laser scanning and photogrammetry}

A laser scanning survey was carried out to capture the irregular shape of the bridge. The complexity and the size of the bridge required 77 scans registered with the use of the geodetic network. The instrument used is a Faro Focus 3D and the final point cloud is made up of 2.5 billion points (Fig. 2a).

The instrument was placed in different positions, including the road and the riverbanks. The survey of the vaults required the creation of a mobile metal structure that allowed one to capture the intrados of the vaults (Fig. 2b).
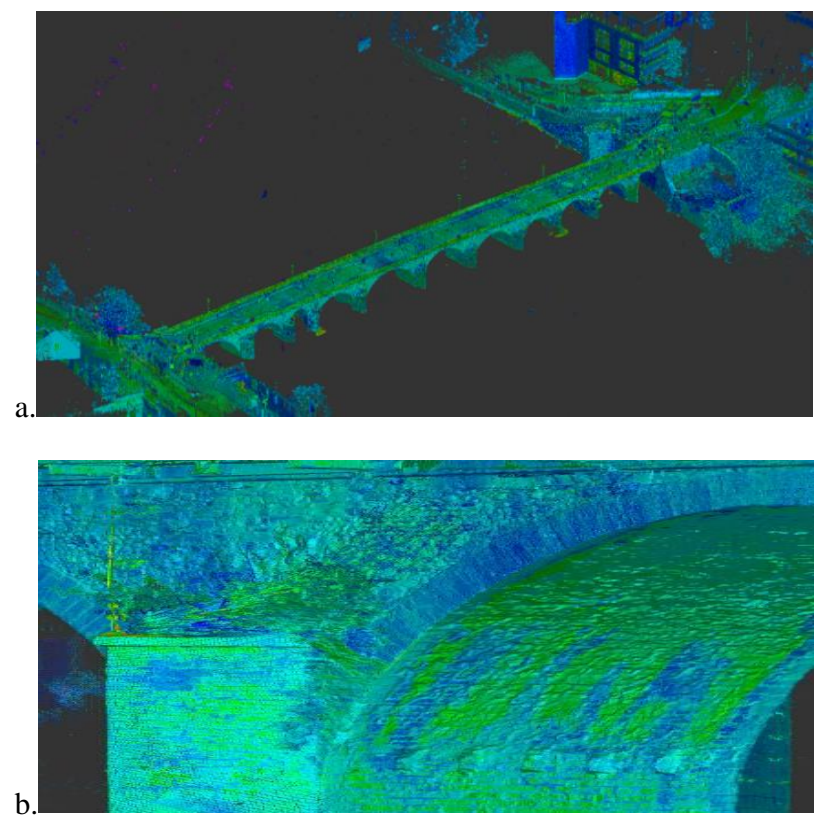

Figure 2. Some images of the laser scanning survey: the overall bridge (a) and a detail of the intrados of a volt (b).
A geodetic network provided a robust reference system to remove deformation during scan registration. The network is made up of 6 stations and the measurement phase took one day. In all, 834 observations and 264 unknowns gave 570 degrees of freedom. Least Squares adjustment provided an average point precision of about $\pm 1.5 \mathrm{~mm}$.

Scans were registered with an average precision of $\pm 3 \mathrm{~mm}$ by using checkerboard targets measured with the total station and additional scan-to-scan correspondence (spherical targets).

The laser scanning survey was then integrated with more than 500 images captured from a boat. Photogrammetry was used to generate accurate orthophotos of the elevations (South and North), the columns and the vaulted surfaces (intrados). Images were oriented via bundle adjustment, then orthophotos were generated by reprojecting multiple images on the $3 \mathrm{D}$ model.

The last step was the projection of the textured model on a plane. Orthophotos were useful to analyze the object because they provide a photorealistic visualization. They were used in different stages of the project, for instance for planning the location of destructive and non-destructive analysis and a complete stratigraphic analysis (Fig.3)
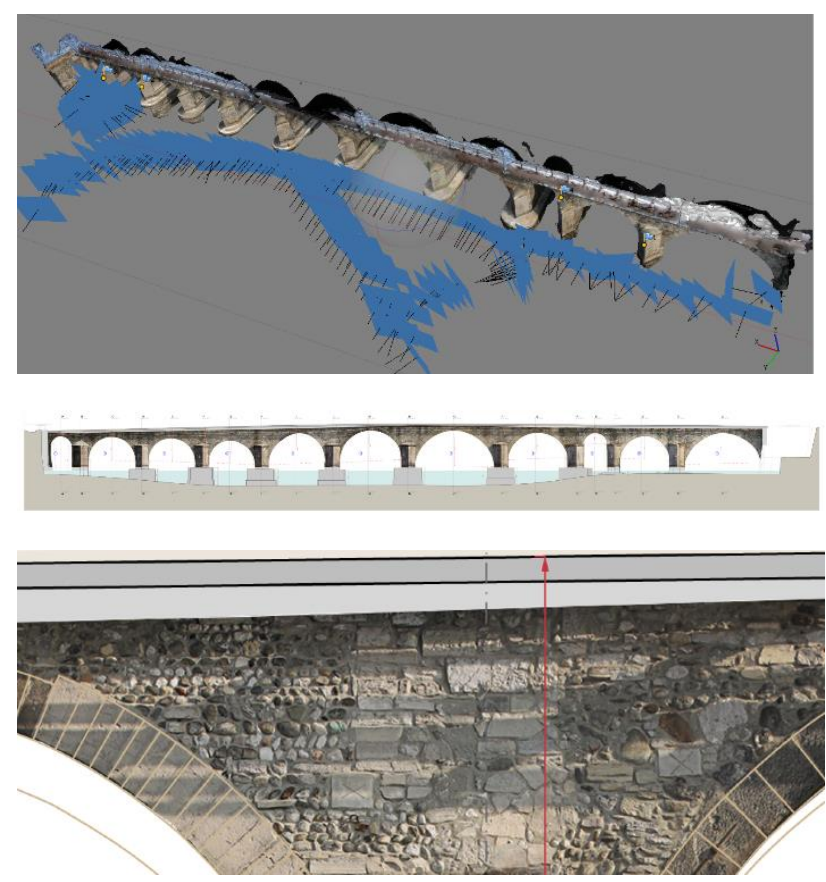

Figure 3. Some of the images (top) of the bridge acquired from a boat and then used to create digital orthophotos (bottom).

\subsection{Geometric levelling}

A geometric levelling was established to monitor vertical movements of the bridge during its testing phase. In particular, a series of trucks and metallic coils were used to test the bearing capacity by alternately loading the different bridge spans. To determine the deformation of the bridge under these loads an high accuracy geometric levelling was performed.

A geometric levelling is performed by using: (a) a level, and (b) a set of leveling rods. A high accuracy level equipped with a pendulum or a compensator create a horizontal line of sight; levelling rods must have a regular graduation to obtain the scale of the levelled differences. According to the basic principle of levelling, the difference between two readings is the height difference. 
The process is repeated to obtain the height difference between backsight and foresight so that the total height difference between widely separated points can be measured by combining the height differences of intermediate points.

In the case of the bridge, the use of an optical level with the parallel plate glass micrometers gave the opportunity to improve reading precision. Rods with 5 -mm graduations were employed, for which the collimation of the nearest reading with an adjustment screw is directly connected to the displacement measured by a micrometer. This provides readings with a precision of $\pm 0.05 \mathrm{~mm}$, that are then estimated to $\pm 0.005 \mathrm{~mm}$. The monitoring project of the bridge was carried out with 47 benchmarks. A benchmark is considered fixed if it is connected to the structure so that it follows its movement. The design of an appropriate measurement scheme coupled with precise measurements allows the determination of heights (and height variations for data taken at different epochs) with sub-millimeter precision.

The design of optimal acquisition nets has a direct impact on the precision: series of closed loops with common points must be preferred to (i) improve the accuracy and (ii) to obtain an immediate check based on misclosures.

The final scheme for the bridge is illustrated in Fig. 4. The adjustment of the network can be carried out via least squares. The observation equations $(\mathrm{Hj}-\mathrm{Hi}=\Delta \mathrm{i}, \mathrm{j})$ give a design matrix A made up of zeros and \pm 1 . The problem is in the form $A x=b+v$, where $\mathrm{b}$ contains the observations, and $\mathrm{v}$ is the residual vector. The solution is $x=\left(A^{T} W A\right)^{-1} A^{T} W b$, where $W$ is a weight matrix (identity matrix for the network of the bridge). Finally, the covariance matrix of parameters can be estimated as $\mathrm{Cxx}=$ $\sigma_{0}^{2}(\text { ATWA })^{-1}$. The precision of heights (after least squares adjustment) was about $0.15 \mathrm{~mm}$ for the different tests carried with different load conditions by means of a heavy truck. The network was measured at different epochs to determine vertical displacements with a simple difference of $\mathrm{H}$ coordinates. Points 10000, 2000 and 3000 were assumed as fixed benchmark because they are outside the bridge.
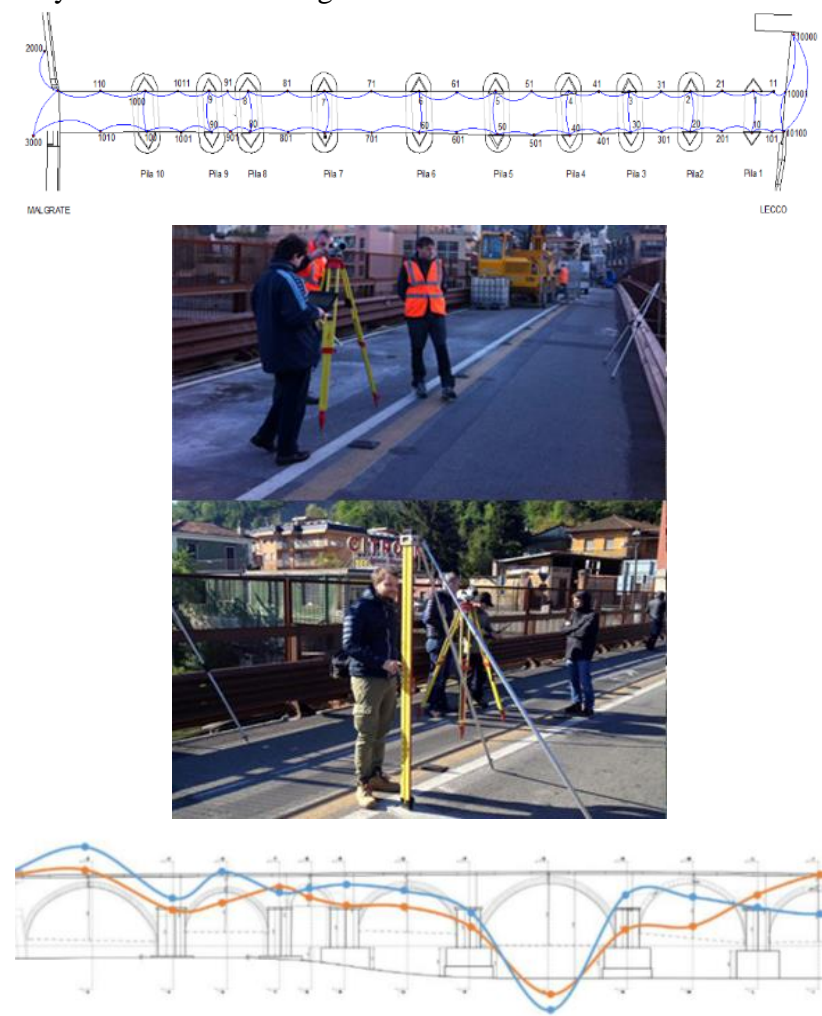

Figure 4. Levelling network scheme, measurement phase, and achieved graphic representation.

\section{3D DATA PROCESSING}

One of the aims of the project was the use of Building Information Modeling (BIM), that is becoming an essential task in construction projects. The goal is the creation of an interoperable BIM for the different specialists (engineers, architects, etc.) involved in the project. For this reason, the survey included a historical analysis, the identification of materials, technological aspects, stratigraphic analysis, and information from other inspections such as destructive and non-destructive inspections. This was useful for the generation of plans and sections, but it becomes fundamental for a BIM project. Indeed, laser scanning and photogrammetric techniques can reveal the external layer of construction elements, whereas a BIM is made up of objects with an internal structure.

The creation of the BIM was carried out by considering that different elements of the bridge become advanced objects with parametric functions. Elements can be modified without redrawing and are structured in a database. Objects have relationships to other objects, as well as attributes. Building information modelling was carried out by dividing different structural objects. Chronological, material and stratigraphic aspects were also taken into account. The final BIM was then made available in Autodesk Revit and A360 (for mobile devices).

\subsection{Clustering of data transmissibility.}

The 3D digital survey has produced essentially four types of data (Fig. 5):

1. Point clouds (laser scanning and photogrammetry)

2. High resolution ortophoto: two fronts (north and south facade) and 11 arches (intrados) of the bridge (photogrammetry)

3. Control points and benchmarks position (Total Station)

4. Reports and spreadsheets (Levelling network scheme benchmarks)

These four different types of data had different purposes and required the identification of various skilled operators to work together.

Laser scanning dataset allowed to record the shape of the building and required scan registration and management of large point clouds (30/40 million points per scan). Photogrammetry has allowed the productions of orthophotos with high resolution. Photogrammetry was useful in order to recognize specific parts of the structure undetected by the laser scanner. It gave the complex morphology of the bridge, both the top (top surface, roadway) and the bottom (lower surface arches, river level).

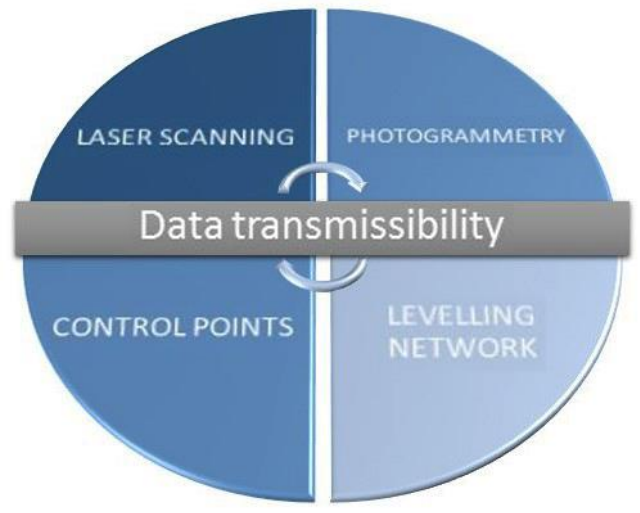

Figure 5. Data transmissibility into H-BIM. 
The use of the total station has produced a map of the surveyed area, provided a three-dimensional reference system for modelling process and increased the registration precision of the point clouds.

Finally, levelling allowed to verify bridge displacement under the testing phase. The data management was implemented via web share Cloud. Autodesk BIM 360 Team has favoured the sharing and the analysis of data between structural engineers, detectors and BIM manager.

\section{IMPLEMETING BIM. THE RESEARCH METHODOLOGY}

The process management of a historical building is characterised by the integration of the latest 3D survey technologies, advanced modelling technique, the most used BIM applications and a central workspace (cloud computing).

The primary requirement during the 3D survey was the collection and management of the different types of data. A lot of scans and control points collected in different periods of the year required a great deal of flexibility of various experts involved in the project. The decision to build a parametric model was taken on the basis of the great potential that this new technology offers all parties involved (surveyors, architects, structural engineers and BIM manager).

Building Information Modelling (BIM) is not only a geometric model but also an accessible database capable of handling different levels of information and phases during the life cycle of a structure such as 3D survey, monitoring, generative process, management and rehabilitation phase. The geometric complexity of the medieval bridge, its typological and morphological characteristics have required the development of a new generative method. The Non Uniform Rational Basis-Splines (NURBS) mathematical models are at present absent in BIM applications. The use and integration of NURBS allowed the generation of the as-built BIM of the complex historical structure (H-BIM), avoiding the base logic of BIM libraries. Subsequently, the parametric model has been useful for the unambiguous association of reports and spreadsheets, favouring the analysis of the structural behaviour and the dissemination of the complex historical values of built heritage.

\subsection{The management of the generative process. Beyond modelling.}

The high level of precision of 3D surveying technologies has required improving the level of accuracy of the digital model. The main goals were: (i) to reach the visualization of micro movements during the levelling process via spreadsheets/graphics and (ii) create as-built BIM characterised by the real complexity of the irregular shapes of the detected structure.

Unfortunately, technologies currently available on the market does not offer a solution capable of directly managing a parametric model with irregular and complex morphological characteristics in a BIM application.

The basic logic of three-dimensional objects included in the BIM libraries and families does not allow a rapid generation of new complex elements. The complexity of buttresses and the bridge arches was extremely difficult to control in BIM applications. The personalization of these new 3D elements required the integration of NURBS technology in order to get the best level of detail and accuracy (LoD 500). The automatic generative algorithms identified in these mathematical models allowed the maintenance of the morphological characteristics of the ancient structure. Autodesk Revit has benefited from this integration (Fig. 6). The direct interpolation of geometric primitives with the point clouds has favoured the implementation of new $3 \mathrm{D}$ constitutive elements of the bridge (rostrums, pillars, arches).

\section{POINT CLOUDS}
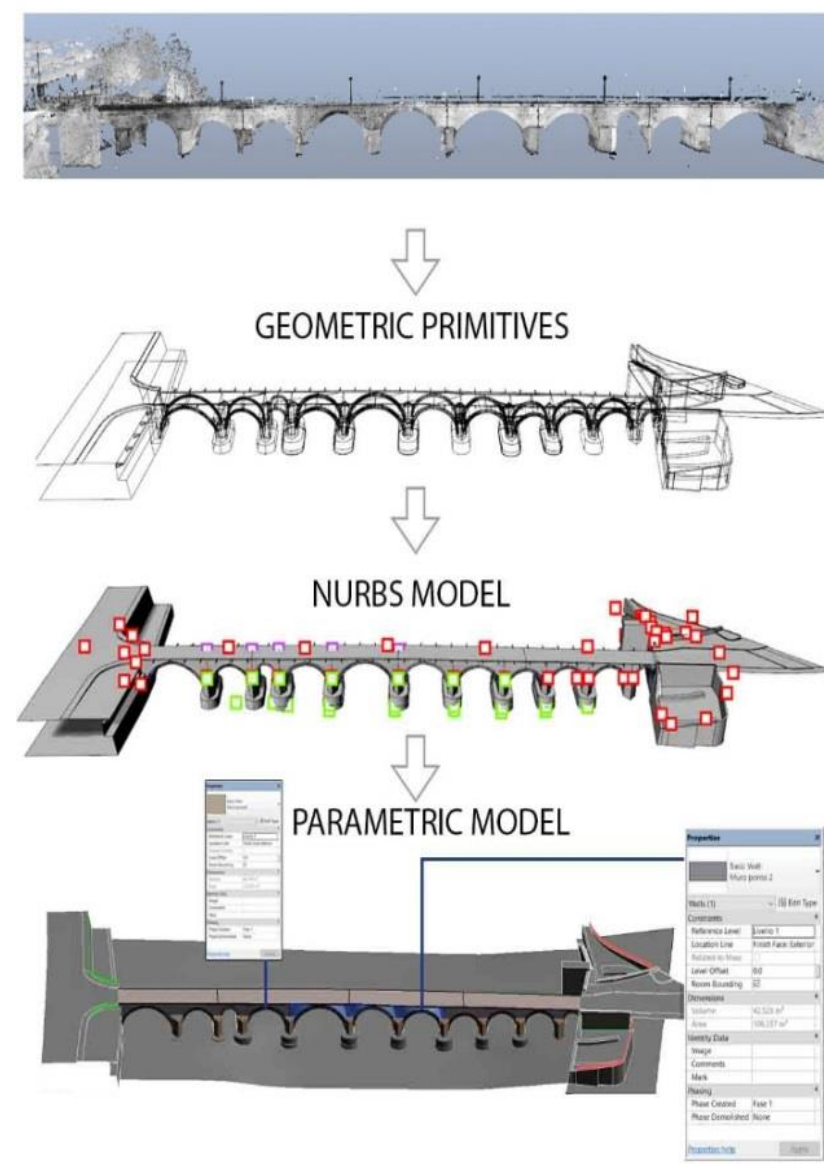

Figure 6. The Generative process. From Point Clouds to Parametric Model (LoD 500).

Finally, the parametric logic of Autodesk Revit allowed the automatic recognition of the surface NURBS, the semi automatic creation of the 3D parametric objects, the integration of stratigraphic information and physical characteristics of the materials and the creation of 3D topography objects (linking the levelling network at the model)(Fig.7).

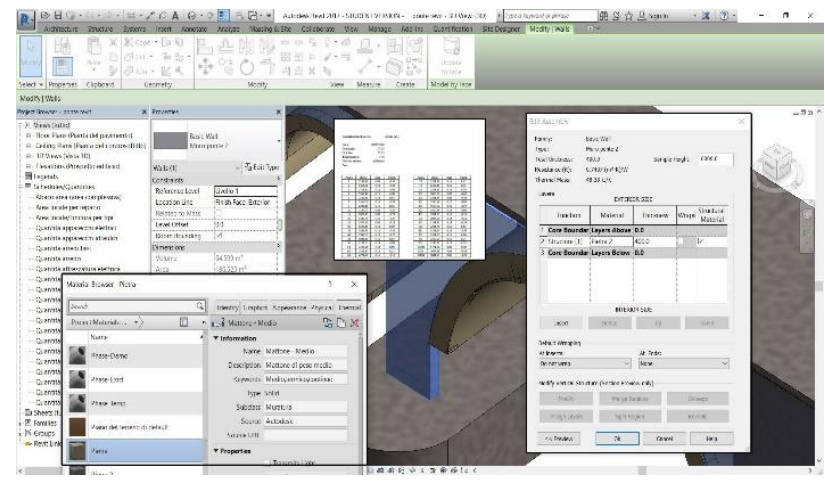

Figure 7. The management of Information System. From Parametric Model (LoD 500) to the integration of stratigraphic information and physical characteristics 


\subsection{Organizing the knowledge. System for archiving and visualizing structural health monitoring (SHM) data}

The need to organize different types of information and guarantee the high quality of collected data required the implementation of a web based archiving system. The implemented digital repository for structural health monitoring allows managing of the structure (tangible value), by using new technology support and implementing the sharing of the knowledge (intangible value) (Fig.8).

\section{Tangible value}

\begin{tabular}{|c|c|c|}
\hline Process & Key components & Benefits \\
\hline $\begin{array}{l}\text { Historic } \\
\text { structure }\end{array}$ & $\begin{array}{l}\text { Material } \\
\text { Documentation } \\
\text { Pathologies } \\
\text { Drawings }\end{array}$ & $\begin{array}{l}\text { Recognition } \\
\text { Log time save } \\
\text { Detection } \\
\text { Digitalization }\end{array}$ \\
\hline $\begin{array}{l}\text { 3D Data } \\
\text { Capture }\end{array}$ & $\begin{array}{l}\text { Laser scanning } \\
\text { Photogrammetry } \\
\text { UAV } \\
\text { Orthophoto }\end{array}$ & $\begin{array}{l}\text { Accurate as-built } \\
\text { Scan integration } \\
\text { Map areas } \\
\text { Specific analysis }\end{array}$ \\
\hline H-BIM & $\begin{array}{l}\text { 3D Objects } \\
\text { Library/Database } \\
\text { Historic elements } \\
\text { NURBS integration } \\
\text { Advanced modelling }\end{array}$ & $\begin{array}{l}\text { 3D coordination } \\
\text { Cataloguing } \\
\text { Customization } \\
\text { Interpolation } \\
\text { Accuracy LoDs }\end{array}$ \\
\hline CLOUD & $\begin{array}{l}\text { Data Sharing } \\
\text { Real time updates } \\
\text { Off line access } \\
\text { On line collaboration } \\
\text { Storage } \\
\text { IT efficiency }\end{array}$ & $\begin{array}{l}\text { Shared goals } \\
\text { External Integration } \\
\text { Scalability } \\
\text { Shared process } \\
\text { Work continuity } \\
\text { Communication }\end{array}$ \\
\hline
\end{tabular}

\section{Intangible value}

Figure 8. H-BIM. From tangible to intangible values of built heritage.

The implementation of Autodesk A360 Team has allowed surveyors and BIM manager to have a high level of communication and visualization in real time.

The system supports more than 100 2D / 3D file formats (among them .dwg, .dxf, .3dm, .pln, OBJ, .sat, .pdf, .doc, .txt, .xls, .pts, etc), in various devices (desktop version and mobile).

The implemented repository was a useful tool for information publishing and several documents were archived and hyperlinked using HTML. Easy-to-use software tools designed specifically to create a high level of sharing are the proper way to find the information quickly. The creation of a parametric model divided into three-dimensional elements corresponding to the structural reality of the structure allowed the development of the information system. The level of detail LoD 500 of the H-BIM is a field-verified 3D representation in terms of location, orientation, quantity, size and shape. The proper generation of accurate 3D Objects such as stone, intrados of arches, sprinter, springing lines, deck, floor beams and stringers has allowed the integration and sharing of non-graphic information in the cloud.

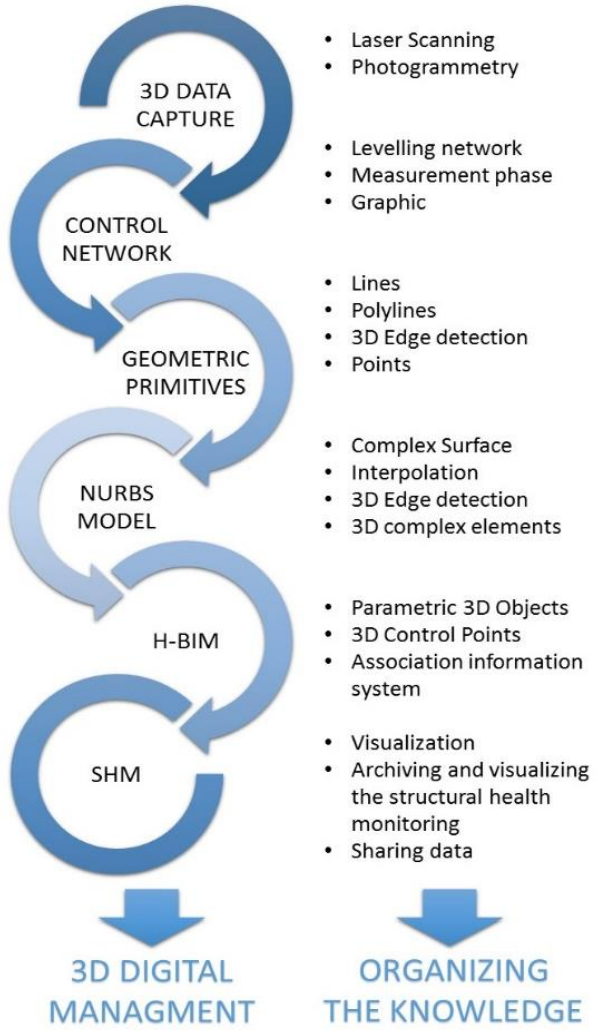

Figure 9. Planning and implementing technology for HumanCentered BIM. The generative process of a historic H-BIM and the system for archiving and visualizing the SHM data.

\section{CONCLUSIONS}

Today, BIM adoption and implementation is the main challenge with several social implications which require optimized work processes. At the same time, research is trying to figure out new solutions in order to optimize the management of built heritage. The management processes enabled by new innovative studies and advanced technologies are changing various operational procedures related to the generation of Building Information Modelling for built heritage. The proposed method addresses social and operational implications of working in a BIM environment, including new shared procedures for different phases: from the survey, cloud sharing, implementation of complex models and specific new structural 3D objects. This paper described a new methodology able to simplify the generative process of a medieval bridge as well as the sharing of related multimedia data into a new repository for structural health monitoring.

Operators in the Architecture, Engineering and Construction (AEC) filed can implement their work processes to become cheaper and more efficient by utilizing the competiteve advantage of H-BIM. The the main feature of the integration of $3 \mathrm{D}$ survey technologies and advanced modelling technique is the ability to locate the geometric primitives of the detected structure through direct analysis of point clouds.

The system set up for archiving and visualizing structural health monitoring (SHM) data allows the connections between different users at the same time and in different places. The integrated use of these technologies and clustering of control protocols allowed the sharing of models, drawings, simulations, data and spreadsheets in a browser, without installing plug-ins or downloads. The creation of shared environment has favoured the 
management over time of the H-BIM of the Azzone Visconti bridge.

In this respect, it is possible to identify, collect, catalogue, and manage data, favouring the future dissemination of tangible and intangible values of cultural built heritage.

\section{ACKNOWLEDGMENTS}

The work was supported by the project Ponte Azzone Visconti Lecco, Indagini, rilievi e verifiche strutturali.

\section{REFERENCES}

Baik, A., Yaagoubi, R., Boehm, J., 2015. Integration of Jeddah Historical BIM and 3D GIS for Documentation and Restoration of Historical Monument. 25th International CIPA Symposium 2015 (XL-5/W7), Taipei, Taiwan, pp. 29-34.

Barazzetti, L., Banfi, F., Brumana, R., Gusmeroli, G., Oreni, D., Previtali, M., Roncoroni, F., Schiantarelli, G., 2015a. BIM from laser clouds and finite element analysis: combining structural analysis and geometric complexity. The International Archives of the Photogrammetry, Remote Sensing and Spatial Information Sciences, Volume XL-5/W4, pp. 345-350.

Barazzetti, L., Banfi, F., Brumana, R., Gusmeroli, G., Previtali, M., Schiantarelli, G., 2015b. Cloud-to-BIM-to-FEM: Structural simulation with accurate historic BIM from laser scans. Simulation Modelling Practice and Theory, Volume 57, September 2015, pp. 71-87.

Barazzetti, L., Banfi, F., Brumana, R., Previtali, M., 2015c. Creation of Parametric BIM Objects from Point Clouds Using NURBS. The Photogrammetric Record, Vol. 30(152), 339-362.

Brujic, D., Ristic, M., Ainsworth, I., 2002. Measurement-based modification of NURBS surfaces. Computer-Aided Design, 24, 173-183.

Brumana, R., Oreni, D., Cuca, B., Binda, L., Condoleo, P., Triggiani, M., 2014. Strategy for integrated surveying techniques finalized to interpretive models in a byzantine church, Mesopotam, Albania. International Journal of Architectural Heritage, 8, pages 886-924.

Dore, C., Murphy, M., McCarthy, S., Brechin, F., Casidy, C., Dirix, E., 2015. Structural Simulations and Conservation Analysis -Historic Building Information Model (HBIM). The International Archives of the Photogrammetry, Remote Sensing and Spatial Information Sciences, Volume XL-5/W4, pp. 351357.

Eastman, C., Teicholz, P., Sacks, R., Liston, K., 2008. BIM Handbook - A guide to Building Information Modeling for owners, managers, designers, engineers, and contractors. John Wiley \& Sons, Inc.

Fai, S., Graham, K., Duckworth, T., Wood, N. and Attar, R., 2011. Building Information Modeling and Heritage Documentation. CIPA 2011 Conference Proceedings: XXIIIrd International CIPA Symposium, 8 pages.

Hu, S.M., Li, Y.F., Ju, T., Zhu, X., 2001. Modifying the shape of NURBS surfaces with geometric constraint. Computer-Aided Design, 33, 903-912.

Murphy, M., McGovern, E., Pavia, S., 2013. Historic Building Information Modelling - Adding intelligence to laser and image based surveys of European classical architecture. ISPRS Journal of Photogrammetry and Remote Sensing, 76, 89-102.

Patraucean, V., Armeni, I., Nahangi, M., Yeung, J., Brilakis, I., Haas, C., 2015. State of research in automatic as-built modelling, Advanced Engineering Informatics, 29 (2), 162-171.

Piegl, L. A., Tiller, W., 1997. The NURBS book. Springer.

Quattrini, R., Malinverni, E.S., Clini, P., Nespeca, R., Orlietti, E., 2015. From TLS to HBIM. High quality semantically-aware $3 \mathrm{~d}$ modeling of complex architecture. The International Archives of the Photogrammetry, Remote Sensing and Spatial Information Sciences, Volume XL-5/W4, 367-374.

Tang, P., Huber, D., Akinci, B., Lipman, R., Lytle, A. (2010). Automatic reconstruction of as-built building information models from laser-scanned point clouds: A review of related techniques. Automation in Construction, 19, 829-843.

Volk, R., Stengel, J., Schultmann, F., 2014. Building Information Modeling (BIM) for existing buildings - Literature review and future needs. Automation in Construction, 38, 109-127. 